\title{
Las viejas fronteras revisitadas: problematizando la formación territorial de los bordes de los Estados-nación latinoamericanos a través del caso de la Norpatagonia Argentina*
}

\author{
The old boundaries revisited: questioning the territorial formation \\ of the edges of the Latin American Nation-States through the case of \\ Argentine Norpatagonia
}

\author{
Pedro Navarro Floria**
}

\section{RESUMEN}

Los espacios conocidos como fronteras, bordes o márgenes de los sistemas coloniales y nacionales de los siglos XVIII y XIX presentan todavía hoy problemas que se expresan en sus representaciones sociales. Prácticas espaciales como la creación de áreas naturales protegidas, circuitos turísticos o corredores de circulación son al mismo tiempo dependientes y generadoras de procesos de valorización diferenciada, desarrollo desigual y funcionalización por el sistema hegemónico. Esto se muestra en el caso de la Norpatagonia argentina pero se propone como hipótesis para otros espacios marginales latinoamericanos.

Palabras Claves: Fronteras. Prácticas espaciales. Formación territorial. Desarrollo desigual. Patagonia.

\section{ABSTRACT}

Spaces known as frontiers, borderlands, or margins of colonial and national systems of the XVIIIth and XIXth centuries still have problems that are expressed in their social representations. Spatial practices such as the creation of protected natural areas, tourist circuits or corridors of trade are both dependent and generating processes of differentiated recovery, uneven development and functionalization by the hegemonic system. This is shown in the case of Argentine Norpatagonia but is proposed as hypotheses for other marginal areas of Latin America.

KEYWORDS: Borders. Spatial practices. Territorial making. Uneven development. Patagônia.

\section{Introducción}

Uno de los problemas en los que mejor se percibe el impacto del pasado sobre la actualidad y de los procesos del mundo actual en territorios con historia, es el de los roles que cumplen algunas regiones de nuestro país -y de distintos países latinoamericanos- en la dinámica actual de la circulación y los intercambios globales, y

\footnotetext{
* Avances preliminares en esta línea de trabajo fueron presentados en las J ornadas de Estudios Indígenas y Coloniales (San Salvador de Jujuy, 2009) y en las XII Jornadas Interescuelas/ Departamentos de Historia (San Carlos de Bariloche, 2009), y reconozco deudas importantes con las discusiones sostenidas en el marco del proyecto de investigación 40B027 de la Universidad Nacional de Río Negro, "Cultura y espacio: contribuciones a la diacronización del corredor Norpatagonia-Araucanía".

** Investigador Adjunto del Consejo Nacional de Investigaciones Científicas y Técnicas (CONICET, Argentina) en el Instituto de Investigación en Diversidad Cultural y Procesos de Cambio (IIDyPCa), Universidad Nacional de Río Negro.
} 
de las tensiones derivadas de ellos. En particular, nos interesa observar los impactos de esa dinámica en regiones - que desde el punto de vista de esas tendencias son conceptualizadas como corredores- relativamente marginales, caracterizadas en los siglos pasados como fronteras o desiertos, incorporadas tardíamente y deficientemente a los sistemas estatales-nacionales de la Argentina y de países limítrofes.

Nuestro interés proviene del análisis del desarrollo histórico de la Patagonia Norte argentina (actuales provincias de Neuquén y Río Negro) y de la constatación de que los mecanismos que desde un punto de vista central podrían caracterizarse por su voracidad como de "acumulación originaria", típicos de los bordes del capitalismo, se han constituido allí en una matriz permanente, que algunos denominan hoy "economía de rapiña" (GALAFASSI, 2010). Proponemos poner en tensión la historia de algunas prácticas espaciales tales como la apropiación, distribución y explotación de la tierra, la creación de áreas naturales protegidas o la turistificación, todas ellas conectadas a través de procesos de valorización diferenciada, con proyectos actuales de facilitación de negocios a gran escala, teledirigidos desde arriba y a través de las políticas estatales neoliberales. ¿No son, acaso, los lugares de dificultosa articulación horizontal en el pasado los más fácilmente "verticalizados" en el presente, es decir funcionalizados por actores hegemónicos a menudo lejanos, o sometidos a la nueva lógica de la globalización del capital?

\section{Una Mirada Sobre la Historiografía de las Fronteras}

La historiografía del último cuarto de siglo sobre las fronteras americanas de los siglos XVIII y XIX ha experimentado un crecimiento y una profundización notables. ${ }^{2}$ La razón para que la atención de los historiadores se haya centrado en esos siglos proviene de la revisión de la periodización decimonónica que hacía hincapié en el acontecimiento de las revoluciones independentistas como hecho fundante. La formación de las naciones latinoamericanas ha pasado a ser vista como el resultado de un largo proceso de "reforma y disolución de los imperios ibéricos" (HALPERIN DONGHI, 1985, 1969), entre 1750 y 1850. Las claves de la construcción identitaria de las naciones latinoamericanas modernas se encontrarían en una extensa crisis colonial seguida de una no menos "larga espera" y no sólo en la coyuntura política de la independencia. Ese desgranamiento del orden colonial latinoamericano se superpone, al menos a partir de las independencias, con la construcción de un nuevo orden

\footnotetext{
2 Existen varios intentos de síntesis y de establecimiento de sucesivos estados de la cuestión. Dos ejemplos, uno desde la historia colonial y otro desde el presente, pueden ser Schröter (2001) y Hevilla (1998).
} 
republicano - si se atiende a sus formas político-institucionales- y neocolonial - si se advierten las modalidades de su inserción en el sistema mundial.

Otro cambio importante, proveniente del campo de la Historia Económica para el caso de la Argentina, ha sido la invalidación de la matriz del territorio nacional para interpretar la dinámica espacial colonial, y el análisis surgido en torno del eje Potosí-Buenos Aires (MOUTOUKIAS, 1999, p. 52). Esto ha permitido interpretar de qué modo, en un momento como el del ascenso del Litoral entre mediados del siglo XVIII y mediados del XIX, que coincide con el mencionado proceso de construcción estatal, una de las principales modificaciones es precisamente la del equilibrio interregional argentino.

Tanto el ciclo de las reformas ilustradas del XVIII como el de la construcción de los Estados del XIX contuvieron una fuerte preocupación por el componente territorial. En el primer caso, con el propósito de determinar y consolidar los alcances y límites de unos imperios coloniales que se percibían amenazados tanto por la competencia externa como por sus contradicciones internas. ${ }^{3}$ En el segundo momento, con el objetivo de extender el espacio de dominación de los nuevos Estados sobre los territorios no conquistados anteriormente por ser considerados inhóspitos o por la resistencia indígena, representados como vacíos, "salvajes" o "desiertos", y por el interés - derivado de la ocupación de los espacios concebidos como "fronteras internas"- en determinar con claridad los límites con los Estados vecinos. La transformación conceptual de los territorios no estatales en "desiertos" y la consiguiente privación de derechos sobre ellos de las naciones indígenas preexistentes (NAVARRO FLORIA, 2002; ROULET; NAVARRO FLORIA, 2005, p. 16-21) fue uno de los procesos característicos de esa época de transición.

La intensidad de una "preocupación territorial" que a veces llegó a ser una obsesión (BOHOSLAVSKY, 2006a, p. 1; 2006b, p.18) parece ser, en el caso latinoamericano, una característica derivada - como señalan diversos estudios recientes- de la insuficiencia de "la raza, la lengua o la cultura" y aún del pacto civil como criterios para la "fundación de la nacionalidad" (CAVALERI, 2004, p.12). Quijada (2000), en su estudio del caso argentino, identifica lo que llama la "alquimia de la tierra" como un componente clave de la matriz de nación cívica opuesto al de nación étnica: lo único que todos los argentinos - indígenas, criollos, inmigrantes del XIX y del $\mathrm{XX}$, no ligados entre sí por linajes- tendrían en común sería la experiencia de compartir un territorio. De ahí la deshistorización de ese territorio - es decir, la idea de que se

3 Para el caso del extremo sur del imperio español. (NAVARRO FLORIA, 1994). 
trata de "un espacio que se percibe como habiendo estado siempre" igual (QUIJ ADA, 2000, p. 182)- y su exaltación a la categoría de componente primordial de la nacionalidad. Y de ahí también nuestra necesidad de rehistorización de los procesos temporales y espaciales de formación de los territorios nacionales como parte de la revisión de los paradigmas nacionalistas relacionados con los nuevos modelos de integración latinoamericana.

La rehistorización de las fronteras latinoamericanas de los siglos XVIII y XIX ha tenido derivaciones hacia otras zonas de la cronología histórica. Hacia épocas anteriores, por ejemplo, mediante la consideración de la conquista de los siglos XVI y XVII como una intrincada serie de procesos de ningún modo unilineales ni repentinos, en los que se ponían en juego intereses, fuerzas, marchas y contramarchas, negociaciones y transacciones. Y hacia el siglo XX, en una importante serie de trabajos nuevos que analizan la formación territorial de los Estados latinoamericanos como procesos conflictivos, multifacéticos y en alguna medida inconclusos. Una obra prestigiosa y reciente de historia de América Latina señala que regiones como la Amazonia, la Araucanía, Yucatán, el noroeste de México y otras contenían "pueblos enteros que en 1870 aún no habían sido introducidos en la economía nacional o que ni siquiera habían sido 'pacificados"' debido a su resistencia o a la escasez de recursos regionales, como los yaquis y apaches de Sonora, los mayas de Yucatán y Quintana Róo, los araucanos del sur de Chile o la gente del Putumayo (BAUER, 1991, p. 159-161). Sin embargo, esta historiografía unidireccional, asimilable a lo que Fontana (2001, p. 329) llama "una fábula de progreso universal en términos eurocéntricos", nos ha ocultado la regularidad de muchos procesos comunes, la complejidad y diversidad interna de nuestras sociedades y los repliegues temporales del espacio continental. En referencia a las áreas marginales de América Latina, el resultado más claro de esto ha sido la consideración de que su historia "comienza" o "llega" cuando estos espacios son apropiados por el Estado - en el caso norpatagónico, mediante la conquista violenta en 1875-1885- y articulados, de algún modo, a los respectivos sistemas estatalesnacionales.

El análisis de los espacios de frontera contiene, entonces, un cuestionamiento de la historiografía y de la narrativa decimonónicas, funcionales a la construcción cultural de las nuevas naciones, que interpretaban la dinámica fronteriza a través de la matriz dicotómica civilización/barbarie, nación/desierto, adentro/afuera, naturalizando la conquista e imaginando escenarios nacionales de bordes bien definidos, sin áreas borrosas y sin posibilidades de discusión del orden en formación. 
El interés en la formación de los Estados y, particularmente, en sus aspectos territoriales, se ve renovado en el siglo XXI tanto por la globalización del capitalismo como por la consiguiente crisis de la idea decimonónica del Estado-nación manifestada, entre otros factores, en el surgimiento de instancias tanto supraestatales - los bloques regionales- como infraestatales - regiones internas, entes de desarrollo, naciones indígenas, etc.- o paraestatales - el capital internacional- que reclaman para sí fragmentos de una soberanía que ya nadie atribuye, en el mundo actual, en forma unívoca y exclusiva a los Estados nacionales. La producción racional de un espacio crecientemente internacionalizado, la "transformación de los territorios nacionales en espacios nacionales de la economía internacional" (SANTOS, 1993, p. 71), es una característica de la globalización que debe atraer particularmente la atención de las ciencias sociales.

\section{Una Mirada Comparada Sobre los Procesos Territoriales Latinoamericanos}

En el contexto de estos procesos emergen como objetos de interés y de análisis histórico esos espacios marginales tardíamente, conflictivamente e insuficientemente articulados con los Estados nacionales creados en el siglo XIX, y hoy a menudo revalorizados por sus "recursos", por su funcionalidad a nuevos ejes de integración o por otros factores. En la mayoría de los casos, los territorios marginales resultan ser espacios limítrofes entre Estados. Por lo tanto, en ellos se jugó, en el pasado, la determinación del alcance de las respectivas soberanías territoriales, y se juegan, en el presente, los procesos de integración binacional y de globalización. Si ningún territorio puede mantenerse al margen de esto, las oportunidades y amenazas que estos fenómenos suponen deben ser evaluadas a la luz de la historia específica de cada territorio (BERVEJ ILLO, 1996, p. 3).

La perspectiva que estimamos más interesante para el análisis de esos espacios marginales de los territorios estatales, es, entonces, la que pone en el foco de observación las funciones que esos espacios han desempeñado y desempeñan en el contexto de los Estados formados en el siglo XIX. Esvertit Cobes (1998, p. 40) identifica dos funciones básicas de las políticas de los Estados latinoamericanos hacia sus márgenes. Se habrían constituido, en primer lugar, en referentes ideológicos eficaces para la producción de nacionalismos diferenciadores hacia afuera y aglutinadores hacia adentro, y, en segundo lugar, en espacios de proyección de las expectativas y los intereses de las élites u oligarquías gobernantes. Atendiendo a una concepción del 
Estado y hasta de la Modernidad misma que considera a la relación entre las administraciones estatales y las periferias como dispositivos coloniales representativos de los intereses dominantes y configuradores de sentidos comunes amplios y profundos (SERJ E, 2005, p. 17), y trasladando esa lógica desde el nivel del sistema global hasta el del sistema estatal-nacional, "la consolidación de la identidad del centro implica la reificación de sus márgenes" (SERJ E, 2005, p. 6). Del mismo modo, se ha estudiado cómo la "literatura de frontera" generada fundamentalmente por viajeros metropolitanos en los márgenes del mundo explorado y sistemáticamente conocido, produjo durante el siglo XIX los territorios nacionales reenviando desde las periferias a los centros preguntas claves acerca de la propia entidad e identidad de los centros de poder y de sus relaciones con los espacios lejanos (FERNÁNDEZ BRAVO, 1999, p. 17). También el relevamiento y el inventario de la naturaleza de los espacios recién conquistados, a fines del siglo XIX -al tiempo que borra las historias y geografías locales para reescribirlas en otra lengua-, se convirtió en una narración del progreso futuro relatando, en realidad, una historia natural y moral de las naciones deseadas, desde sus confines mismos (NAVARRO FLORIA, 2006a).

Desde el punto de vista de los intereses y expectativas de las élites gobernantes, el norte mexicano, la Amazonia compartida por Venezuela, Colombia, Ecuador, Perú, Bolivia y Brasil, el Mato Grosso brasileño, el Chaco boliviano, paraguayo y argentino, la Araucanía chilena, la Patagonia argentina y chilena y sin duda muchas otras regiones de América Latina fueron y son aún hoy objeto de prácticas de apropiación simbólica y material tales como la conquista y el sometimiento de las poblaciones preexistentes -indígenas, mestizas y renegadas-, la integración subordinada de esas poblaciones en los mercados de trabajo, la delimitación, la exploración por naturalistas o funcionarios más o menos dependientes de los Estados y el inventariado de los bienes comunes en términos de "recursos", la exhibición internacional de la disponibilidad de esos bienes, el levantamiento cartográfico, la evangelización mediante misiones generalmente católicas, la colonización pública o privada, la conversión de las tierras indígenas en tierras fiscales y su redistribución mediante diversas operaciones obedientes a la lógica del mercado, la apertura de vías de comunicación y la realización de otras obras de infraestructura y fomento económico. Sin embargo de todas esas iniciativas a través de las cuales los sectores dominantes procuraron extender sus negocios y sus ámbitos de dominación, los procesos de nacionalización de los márgenes - término que puede tomarse como mínimo común denominador de las prácticas de los Estados latinoamericanos sobre sus espacios fronterizos- parecen haber producido resultados muy por debajo de las 
expectativas formuladas en el discurso triunfalista de los nation builders decimonónicos. Términos como estancamiento económico, ineficacia y debilidad estatal, continuidad colonial o colonialismo interno, desconocimiento del espacio, discrepancia entre el territorio reclamado y el efectivamente controlado por el Estado, generalización del latifundio improductivo, articulación deficiente y/ o tardía con los sistemas nacionales, etc., se repiten en diversos análisis sobre distintos países de la región (Esvertit Cobes, sobre el oriente ecuatoriano; Sala i Vila, sobre la Amazonia peruana; Teruel, y Lagos y Santamaría, sobre el Chaco argentino; Pinto Rodríguez, sobre la Araucanía chilena; Nicolau, sobre la Amazonia brasileña; etc.). En el vocabulario de las ciencias sociales del siglo XX este conjunto de problemas se resumía en el concepto de subdesarrollo, y en el siglo XXI parece constituir el menú de las debilidades estructurales.

Tanto las expectativas de las élites como las limitaciones de los aparatos estatales se vieron reflejadas en la construcción institucional de territorios de frontera, de colonización o de avanzada pionera en manos de los Estados nacionales. Venezuela tuvo sus “Territorios Federales”, entre ellos el de Amazonas, transformados en Estados recién en la década de 1990. Otras naciones de estructura política federal, como Argentina y Brasil, siguieron procesos similares. Argentina creó Territorios Nacionales entre 1862 y 1878 y los organizó definitivamente en 1884, sin poder cumplir el propósito proclamado inicialmente, de crear nuevos Estados provinciales - según el modelo estadounidense-, hasta pasado 1950 (RUFFINI, 2007, p. 79-88). Finalmente, convirtió en Provincia su último Territorio, el de Tierra del Fuego, en 1990. Una situación especial se vivió, incluso, en territorios sobre los que las provincias habían avanzado y que resultaron apropiados por la Nación mediante arreglos transaccionales realizados en el Congreso. Es el caso de Salta respecto del Chaco, de Corrientes respecto de Misiones y de Buenos Aires respecto de la Pampa y Patagonia (RUFFINI, 2007, p. 32-33; NAVARRO FLORIA, 2003, p. 63-64). Sin embargo, la Provincia de Buenos Aires conservó su avanzada sobre el río Negro y Mendoza también supo defender su porción norpatagónica. Brasil creó en 1943, en el marco de las tensiones nacionalistas de la primera mitad del siglo XX, los Territorios Federales de Rio Branco (luego Roraima, en el norte de la Amazonia lindante con Venezuela), Guaporé (luego Rondônia, lindante con Bolivia), Amapá (lindante con las Guayanas), Iguassú (lindante con Argentina) y Ponta Porã (lindante con Paraguay), pero los últimos fueron transformados en Estados en 1988.

Países unitarios como Colombia y Chile pudieron disponer desde sus administraciones centrales, con más flexibilidad, de sus espacios territoriales. Chile 
creó tempranamente, en 1853, los Territorios de Colonización de Llanquihue y de Magallanes, en 1875 el de Angol y en 1927 el de Aisén, pero los fue transformando sucesivamente en Provincias, como también a la Araucanía a fines del siglo XIX. Colombia, al nacer como estado, contaba con un 75\% de su espacio, fundamentalmente en las tierras bajas orientales de Orinoquia y Amazonia, bajo la forma de Territorios Nacionales, que fueron convertidos en Departamentos en 1991.

Algunos trabajos llaman la atención acerca de una verdadera inversión de las expectativas iniciales sobre los espacios fronterizos. En diversas regiones incorporadas por la Argentina, la conquista violenta fue encubierta bajo el aparente avance pacífico de la "civilización”, como en el caso de la “Campaña del Desierto” a la Pampa argentina. En otro momento hemos trabajado sobre la nacionalización fallida de la Patagonia (NAVARRO FLORIA, 2003) y el concepto se proyecta sobre el siglo XX en forma de planificación fallida de zonas de seguridad, áreas de frontera, regiones-programa, etc., al menos en términos de integración en la nación4. Esto contribuyó a que, todavía entrado el siglo XX, el crecimiento económico y el optimismo argentino debieran circunscribirse a un radio de 800 kilómetros de Buenos Aires, y a que el Chaco y la Patagonia siguieran siendo considerados casi desiertos, excepto por algunos escasos enclaves (ROCK, 1991, p. 68-70, 75-77). Lagos y Santamaría (2008) demuestran cómo las políticas hacia el Chaco atravesado por el Bermejo constituyeron una verdadera construcción del desierto. Para Chile, León Solís (2005) ha analizado detenidamente de qué modo las operaciones del Estado chileno representadas por tradicionalmente como la "Pacificación de la Araucanía”, resultaron en realidad en una generalización y profundización de la violencia interétnica. Paraguay y Bolivia se disputaron su porción del Chaco en una sangrienta guerra, entre 1932 y 1935, cuando la probable existencia de petróleo en la región la rescató del absoluto olvido en que permanecía. El Perú moderno pareció condenado por su geografía: separado por los Andes el centro político y económico de su territorio de su otra mitad selvática, y soñada ésta como la solución de los problemas de desarrollo nacional aunque nunca integrada plenamente a la nación (KLARÉN, 1991, p. 235). El subcontinente Brasil experimentó durante todo su desarrollo serias dificultades de vinculación física entre sus partes más allá de la franja costera y de Minas Gerais, y produjo una rica historiografía sobre su formación territorial. ${ }^{5}$ Serje (2005, p. 4-5), en su investigación sobre Colombia, muestra la contradicción constituida por las llamadas "zonas de orden público" cuya característica es el desorden, por "territorios nacionales" que resultaron ser "los menos nacionales de

4 Agradezco esta última observación a Alicia Laurín (comunicación personal, 18 dez. 2008).
5 Solamente a modo de ejemplo, remitimos a MAGNOLI, 1997. 
los territorios", por lugares, en fin, que pueden ser considerados el revés de la trama o el negativo fotográfico de la nación.

Esa proyección relativamente fallida de las expectativas de los sectores dominantes sobre los márgenes de las naciones, según inferimos, habría contribuido a realimentar la representación social de esos espacios marginales como condensación de las frustraciones y al mismo tiempo de las esperanzas nacionales, su establecimiento como objetos del deseo, de los mejores planes y proyectos estatales y aún de los más delirantes mitos nacionalistas y conspirativos del siglo XX. Si los state builders del XIX no lograron articular esos espacios en el cuerpo de sus naciones por haber privilegiado su representación primero como desiertos vacíos y en seguida como escenarios del progreso futuro, generando diseños y proyectos de gabinete, más expresivos de su "deseo territorial" (LOIS, 2006) que de conocimientos y posibilidades reales, los nacionalismos del XX, según propone Bohoslavsky (2006a, p. 6-8) para el caso argentino, habrían encontrado allí motivos de interpelación, al mismo tiempo hacia adentro y hacia fuera de la nación. Hacia adentro, en demanda de una mayor “conciencia territorial”. Y también en el campo de las interpretaciones geopolíticas y las relaciones internacionales, advirtiendo a propios y extraños acerca del supuesto "cerco territorial" trazado por los países vecinos-enemigos, y emprendiendo una revisión historiográfica de los límites del territorio estatal. En el caso argentino, por ejemplo, se logró instalar la idea de que el país provendría de un Virreinato del Río de la Plata progresivamente desmembrado por intereses foráneos y que debería ser restaurado (CAVALERI, 2004). Lacoste (2003, p. 343-353) ejemplifica la confrontación de dos nacionalismos especulares con el caso argentino-chileno, que produjo casi simultáneamente, en la primera mitad del siglo XX, tanto la representación de una "Argentina fantástica” históricamente despojada de territorio por Chile, como su reverso: un "Chile fantástico" disminuido por la Argentina. Bohoslavsky (2006a, 2006b) identifica también toda una tradición mítica centrada en la idea de un complot - anarquista, comunista, judío, nazi, inglés, estadounidense o chileno, según el momento- destinado a arrebatarle la Patagonia a la Argentina, y llama la atención acerca de la recurrencia de la connotación geográfica presente en las diversas versiones del discurso nacionalista. De este modo, los nacionalismos sacralizaron el territorio y lograron equiparar soberanía con soberanía territorial, convirtiendo, de ese modo, al territorio en materialización de la identidad nacional.

El proceso actual de globalización reformula los viejos miedos nacionalistas en términos de una serie de amenazas cuya potencialidad se acrecienta en territorios con debilidades estructurales. Además de la marginación o exclusión, la integración 
subordinada y la crisis ambiental, el riesgo de desmembramiento o fragmentación de las viejas unidades territoriales ocupa un lugar importante entre los desafíos que se presentan a las nuevas geografías (BERVEJ ILLO, 1996).

\section{Las Viejas Fronteras y las Nuevas}

En un análisis diacrónico ${ }^{6}$, el espacio norpatagónico articulado también por el eje de un río y su cuenca -el Negro- puede reconocerse como espacio marginal o de frontera en tres grandes etapas:

La Norpatagonia-entrada (siglos XVI-XVIII), se caracterizaría como escenario de entradas esporádicas en busca de ganado, esclavos u oro, pero no motivadas por el interés en fundar establecimientos permanentes ni en someter definitivamente a las naciones indígenas. La conflictividad del proceso de conquista del sur argentino y sus proyecciones sobre la Norpatagonia han sido estudiadas (NOCETTI; MIR, 1997). La región - en realidad, con todos los territorios indígenas independientes de Araucanía, Pampa y Patagonia- constituyó entonces uno de los confines ${ }^{7}$ australes del imperio, transitados esporádicamente pero no dominados ni integrados al sistema de explotación, ocasionalmente convertidos en fronteras de guerra con los mundos indígenas. Mientras los espacios marginales funcionaron como confines, las tensiones entre los mundos locales y el sistema hegemónico en proceso de globalización pueden sintetizarse en la violencia material sufrida por las poblaciones atacadas, desposeídas de sus bienes, esclavizadas, sometidas a regímenes de trabajo forzado, acompañada por la violencia simbólica ejercida por quienes pretendieron, aunque fuera esporádicamente, modificar mentalidades, cosmovisiones, pautas culturales, etc. a través de la política fronteriza.

La Norpatagonia-puente (de fines del XVIII a fines del XIX), se caracteriza por la presencia occidental permanente en los dos extremos del corredor - en la costa

\footnotetext{
${ }^{6}$ Similar al emprendido Lagos y Santamaría (2008) en su trabajo sobre el corredor del río Bermejo, en el cual distinguen cuatro etapas en su funcionamiento: el Bermejo-entrada (siglos XVI-XVIII), el Bermejo-puente (de mediados del XVIII a mediados del XIX), el Bermejo-recurso (de mediados a fines del XIX) y el Bermejo-desierto-planificado (desde su conquista). Cada una de esas etapas se caracterizaría por una visión, una forma de valorización del espacio y una función de este en un sistema más general - los mercados coloniales; el territorio nacional-

7 Hacemos uso del concepto de confín elaborado por Vives Azancot (p.e. 1988:178-179), que hace referencia al límite administrativo y territorial formal de los dominios de la Corona, por contraposición con el hinterland, que sería el límite territorial real. A partir de esa distinción, Vives Azancot fue uno de los pioneros en la historiografía americanista en el análisis del funcionamiento de las estructuras territoriales regionales del sistema colonial español y de la tensión histórica entre la voluntad manipuladora imperial y las diversidades regionales, que sirve para explicar por qué el reformismo borbónico - funcional a un modelo mundial de crecimiento hacia afuera- exacerbó las líneas de fractura y transformó a "las periferias económicas americanas... en laboratorios de los nuevos tiempos" (NAVARRO FLORIA, 1994, p. 175).
} 
atlántica, desde la fundación de Carmen de Patagones en 1779, y en la Araucanía, desde la refundación de Osorno en 1790; y por la colonización tanto del valle inferior del Negro como de la zona de los lagos chilenos a lo largo del siglo XIX-, y también por diversos intentos - sobre todo del sistema colonial- de conectar ambos extremos y de controlar la circulación de personas y bienes por los pasos cordilleranos neuquinos. La diferencia con la etapa anterior viene dada por la iniciativa de la monarquía española de hacerse presente en la Patagonia y de establecer claramente los límites australes del imperio, y por la subsistencia de las ciudades fundadas, después de la crisis de independencia. En esa etapa la región se constituyó en hinterland, desde el momento en que la Corona española lanzó su iniciativa pobladora y colonizadora ante la hipótesis de conflicto con otras potencias europeas y estableció el límite real de sus dominios en el paralelo $40^{\circ}$ al este de los Andes y en el paralelo $44^{\circ}$ en el oeste (NAVARRO FLORIA, 1994, p. 60-61). A lo largo del siglo siguiente continuó un proceso inorgánico de colonización y circulación de personas y mercancías por el corredor de los ríos y pasos cordilleranos norpatagónicos. Este funcionamiento coincide con el del sistema policéntrico de las economías regionales argentinas vinculadas con los países limítrofes (ROFMAN; ROMERO, 1997, p. 105). A las violencias iniciales - que persistieron y se incrementaron progresivamente- se agregó la expropiación de la tierra, que también tuvo su faceta material - el arrinconamiento progresivo- y su faceta simbólica -en el proceso de "domesticación" de la cuestión indígena que contribuyó a representar a los pueblos originarios como "salvajes" y a sus territorios como "desiertos" (ROULET; NAVARRO FLORIA, 2005)-. El deslizamiento de los territorios marginales al interior de los nuevos Estados-nación como "fronteras internas", el tratamiento de sus habitantes como Otros-internos y la consideración de los espacios como disponibles para la expansión de la acción del capitalismo global fueron los resultados de lo que Vives Azancot (1988, p. 175) llama "un nuevo desembarco europeo más técnico, maduro y voraz" que el de la primera conquista.

La Norpatagonia-recurso (a partir de su conquista en la década de 1880), se caracteriza por el abandono de la representación de la región como "desierto" y su resignificación como paisaje del progreso (NAVARRO FLORIA, 2006a, 2007), espacio sobre el que se proyectan las expectativas de desarrollo de los sectores dominantes, desde los liberales reformistas de principios del siglo XX, pasando por los conservadores de la década del '30, el peronismo, el desarrollismo y su Programa Comahue, y hasta el intento fallido de traslado de la Capital Federal a Viedma y los actuales proyectos de corredores bioceánicos e integración regional. En esa etapa la región fue configurada por el Estado nacional como parte del sistema de Territorios 
Nacionales o colonias internas de la nación (NAVARRO FLORIA, 2003, p. 83-84), articulada con el sistema nacional como proveedora de recursos - agropecuarios, paisajísticos, energéticos, etc.- en el marco del sistema centralizado construido por las inversiones extranjeras, la red ferroviaria y caminera (ROFMAN; ROMERO, 1997, p. 134) y últimamente por las iniciativas de planificación supranacional como IIRSA. El proceso de centralización de los mercados internos argentinos fue claramente advertido como clave del proceso territorial por la Geografía de principios del siglo XX (DENIS, 1927, p. 41-48), y el mismo autor señalaba, en ese contexto, que la importancia permanente del corredor norpatagónico "es uno de los hechos más claramente inscritos por la naturaleza sobre el suelo americano". Es de notar la importancia actual de esta configuración colonialista interna, que perpetúa la debilidad estructural de las provincias patagónicas y, por ende, de su articulación en el sistema nacional. Esto se explica por la instalación - no automática ni exenta de demoras, obstáculos y contramarchas, una vez incorporadas las regiones marginales por el Estado nacionaldel "sistema técnico y racional de acciones del capitalismo globalizado" (SANTOS 1993, p. 74) en 'Ios espacios económicos... más evolucionados, los más atractivos, rentables y organizados" (VIVES AZANCOT, 1988, p. 175), generándose los procesos típicos de valorización diferenciada o selectiva de recursos y de crecimiento desigual producidos por la "reconstitución teleguiada de las regiones" (SANTOS, 1993). No debe perderse de vista la relación de funcionalidad existente entre esta articulación neocolonial del espacio nacional y lo que Ruffini (2007) llama "la pervivencia de la República posible" en los Territorios Nacionales, es decir la demora deliberada de los procesos de ciudadanización y autonomización política.

\section{Prácticas Espaciales del Presente Sobre las Viejas (y Nuevas) Fronteras}

La investigación acerca de las construcciones identitarias a partir de la territorialidad y de sus implicaciones para los actuales procesos de integración regional y de globalización supone, necesariamente, el análisis de prácticas espaciales concretas. Algunas de ellas son particularmente expresivas de las funciones cumplidas por los espacios marginales en la formación territorial pasada y actual de los Estados latinoamericanos. Prácticas materiales como el trazado de vías de comunicación, o la creación, a lo largo del siglo XX, de áreas naturales protegidas y turísticas, o la puesta en explotación de la tierra, son ejemplos útiles al respecto. 


\section{a. Las vías de circulación}

Las vías de comunicación que en un primer momento procuraron poner en contacto los centros con las periferias estatales, como las rutas y los ferrocarriles norpatagónicos que conectan la cordillera de los Andes con la costa atlántica y con la Pampa Húmeda, actualmente buscan conectar los centros estatales entre sí - en este caso, mediante la integración con Chile- y con centros de poder extrarregionales, a menudo atravesando espacios que desde antiguo se consideran periféricos.

La Iniciativa para la Integración de la Infraestructura Regional Suramericana (IIRSA) para la articulación del subcontinente con los mercados mundiales contiene, fundamentalmente, la idea de varios ejes de circulación (figura 1), algunos de ellos transversales o bioceánicos, trazados en el sentido de los paralelos. La Argentina es atravesada por varios de ellos. Mientras el Chaco boliviano-paraguayo es cruzado por el Eje Interoceánico Central, el Chaco argentino es atravesado por el Eje de Capricornio, la zona central del país por el Eje Mercosur-Chile y la Norpatagonia por el Eje del Sur.

Figura 1-Ejes de integración y desarrollo propuestos por la Iniciativa para la Integración de la Infraestructura Regional Suramericana (IIRSA)

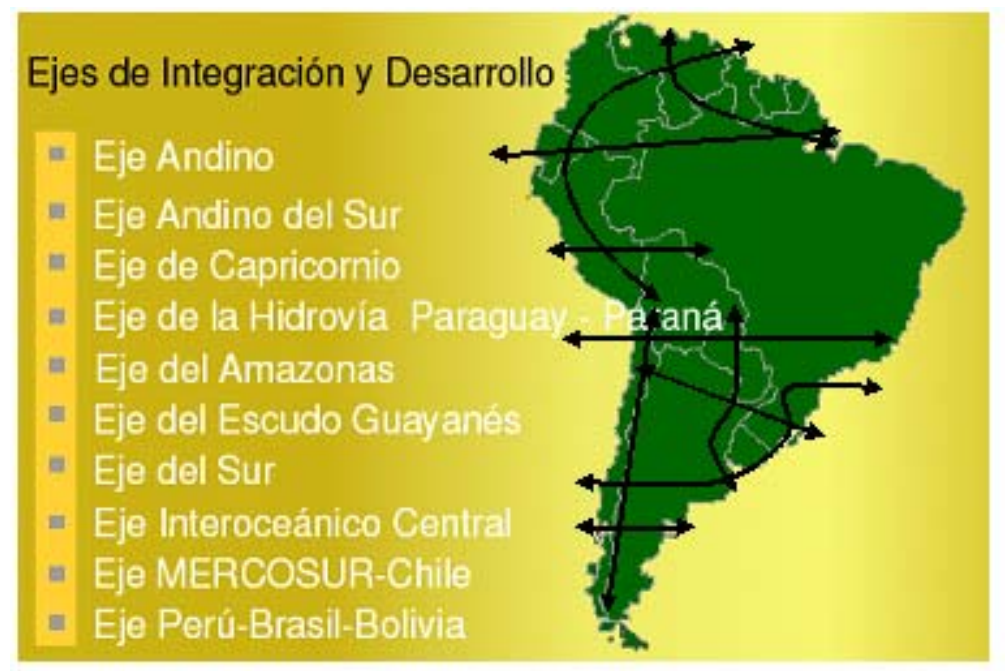

Fuente: elaboración propia a partir de http:// www.iirsa. org.

Estos corredores, que según IIRSA, "son franjas multinacionales de territorio en donde se concentran espacios naturales, asentamientos humanos, zonas productivas y flujos de comercio actuales, sobre las que las inversiones en infraestructura ayudarán a crear nuevas oportunidades de desarrollo sostenible para sus habitantes" (http://www.iirsa.org), cumplen con las expectativas del sistema técnico y racional de acciones del capitalismo globalizado al articular las zonas más dinámicas de la región del Mercosur- con los mercados emergentes de la región Asia-Pacífico, verificando la 
"reconstitución teleguiada de las regiones" (SANTOS, 1993, p. 74). Esto no consistiría, para el caso, más que en la intensificación, en volumen y en velocidad, de la lógica extractiva caracterizada como "economía de rapiña”. En el caso argentino, es fuerte el contraste entre el desarrollo en infraestructura y en intensidad de circulación logrado por el Eje Mercosur-Chile ${ }^{8}$, y el de los otros dos, que recorren áreas marginales como Norpatagonia (figuras 2 y 3 ).

Figura 2 - Eje del Sur, mapa del área de influencia

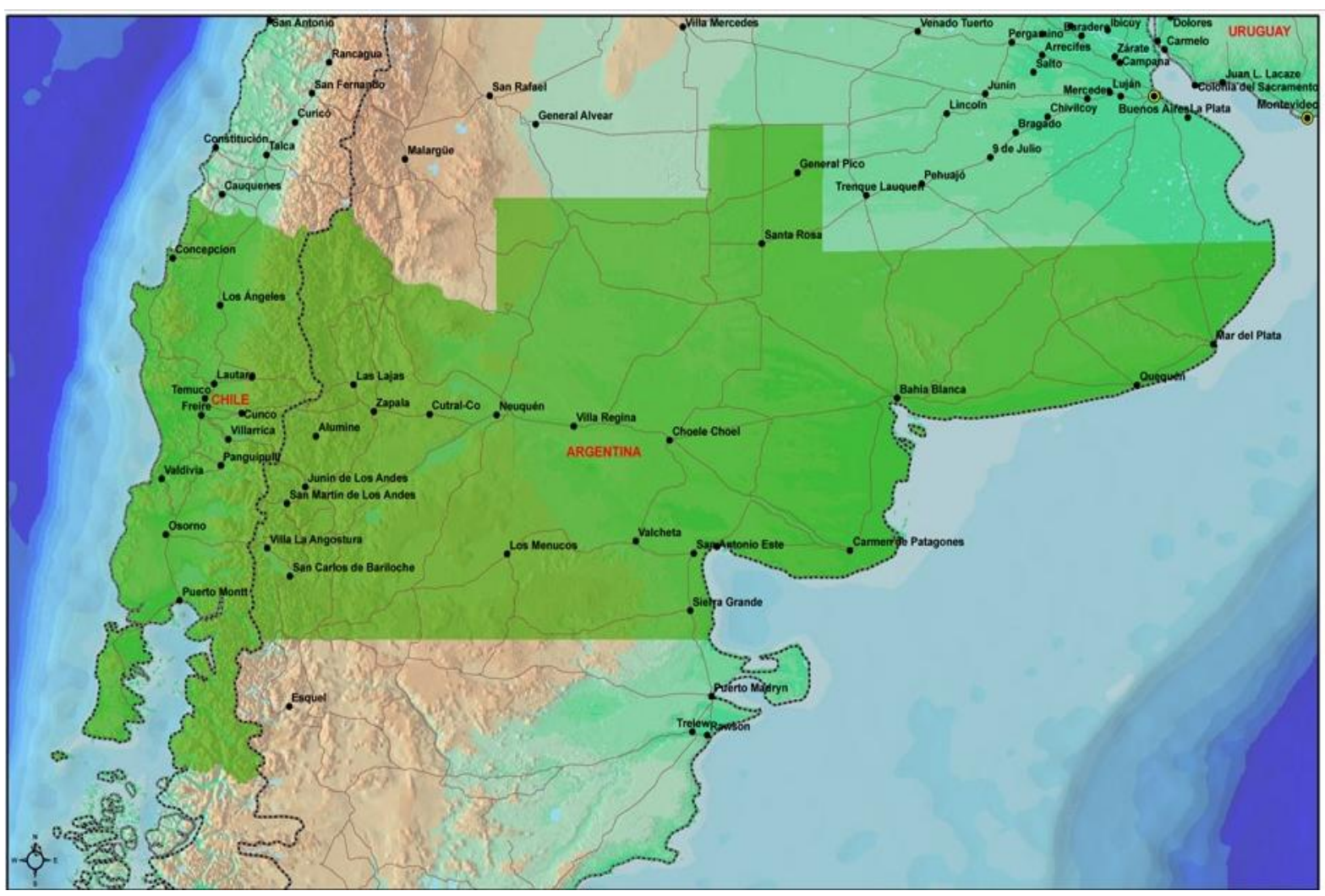

Fuente: http:// www.iirsa.org.

8 Dos análisis interesantes de uno de los subsistemas -el Pehuenche- dependientes de ese gran eje central: uno incluyendo un estudio histórico completo (Lacoste 1998) y el otro a modo de informe de situación de una época clave (CEPPARO; PRIETO, 2008). 
Figura 3 - Eje del Sur, mapa de proyectos del Corredor Bioceánico Concepción Bahía Blanca - San Antonio Este.

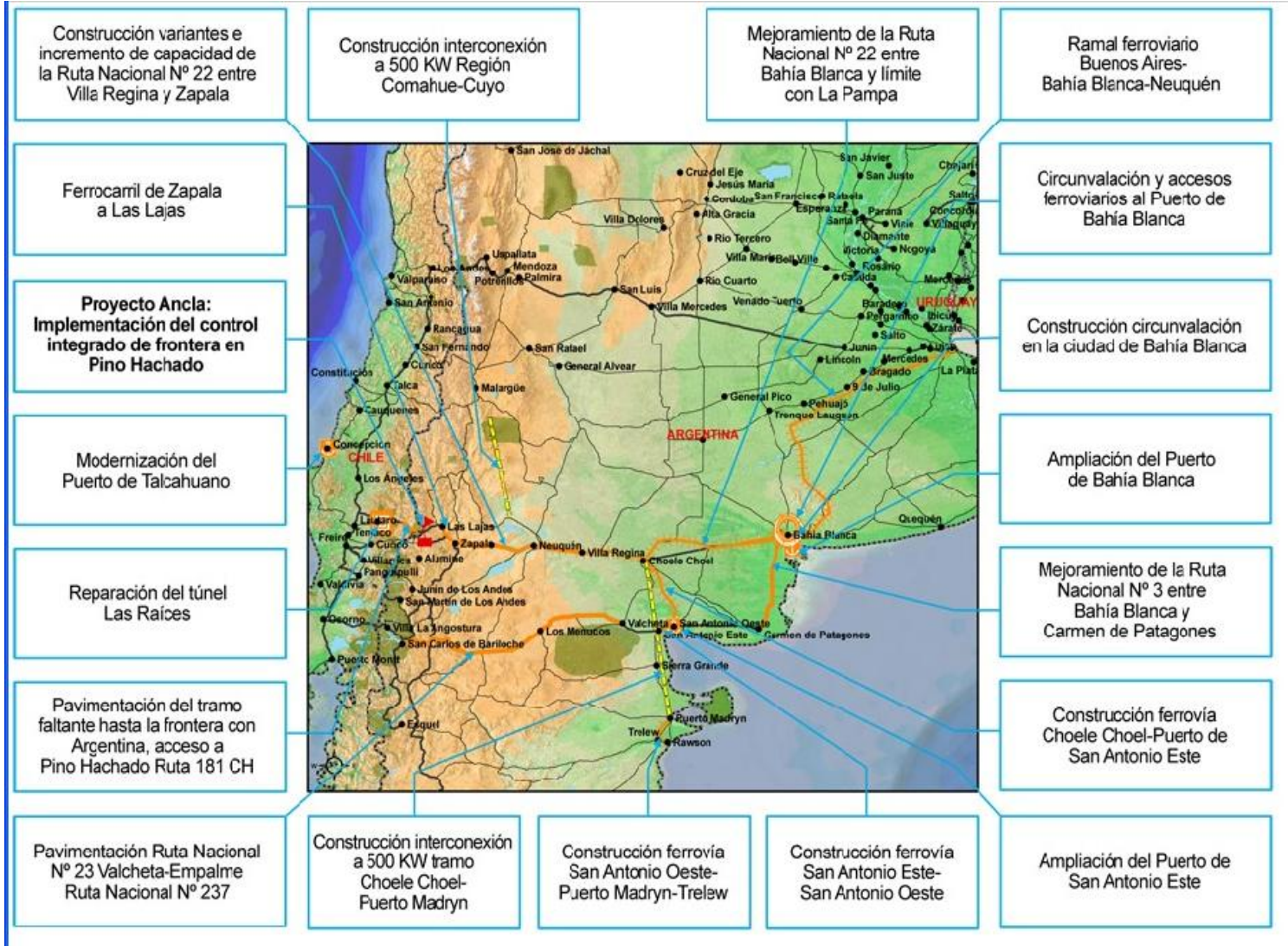

Fuente: http:// www.iirsa.org

Una primera lectura histórica de larga duración nos permite advertir el cambio de lógica espacial de las últimas décadas, ocurrido a favor de los procesos de integración regional y de la globalización del capitalismo. Los corredores transversales - en el sentido de los paralelos- en América del Sur, desde la época colonial, fueron funcionales a los circuitos de intercambio informal o de contrabando, por cuanto vinculaban el mundo andino/ español con el mundo atlántico/brasileño/ portugués, o el mar español - el Paćfico- con el mar internacional - el Atlántico-. Los circuitos formales o legales, en cambio, eran longitudinales, siguiendo el sentido de los meridianos: tanto la ruta marítima a lo largo de la costa pacífica como la columna vertebral Buenos Aires - Potosí, articuladoras de los espacios económicos regionales. Al respecto, son expresivas tanto la historia del comercio entre el Tucumán y el sur de Brasil - inaugurado, según la tradición, por el primer obispo del Tucumán en 1587como la del circuito ganadero indígena entre la Pampa bonaerense y los mercados de la Araucanía, por los ríos y pasos cordilleranos norpatagónicos. 
En la larga transición del régimen colonial al neocolonial -de mediados del siglo XVIII a mediados del XIX- el eje Buenos Aires - Potosí se fracturó por la crisis de independencia y la nueva configuración territorial de los Estados, y en cambio esos corredores transversales se fortalecieron desarrollando el sistema policéntrico (ROFMAN; ROMERO, 1997, p. 105) por el cual cada economía regional se vinculó mejor con sus mercados más cercanos en los países limítrofes que con un mercado nacional relativamente lejano. La formación del Estado y del sistema nacional a partir de mediados del siglo XIX invirtió esa tendencia centrífuga y centralizó los mercados mirando al puerto (ROFMAN; ROMERO, 1997, p. 134). Ese fue el fenómeno central observado por Pierre Denis en la Argentina de la segunda década del siglo XX y volcado en el mapa de los ejes de circulación sudamericanos elaborado para la Geografía Universal dirigida por Vidal de la Blache y Gallois en la década de 1920 (figura 4). En realidad, ese mapa no marca corredores de integración sino algunos ejes de circulación tradicionales y, fundamentalmente, modalidades de transporte que responden al concepto vidaliano de los "géneros de vida" explicativos de los circuitos económicos regionales. Entre los ejes de circulación, en el territorio argentino figuran, significativamente, la "Ruta del Alto Perú al Río de la Plata" tanto por Córdoba como por Santa $\mathrm{Fe}$, los "Antiguos transportes de minerales hacia Chile" por los pasos centrales y la "Ruta de los vacunos de la Pampa robados por los indios" entre el sur de la Provincia de Buenos Aires y el sur de Chile. 
Figura 4 - La circulación en América del Sur, 1927

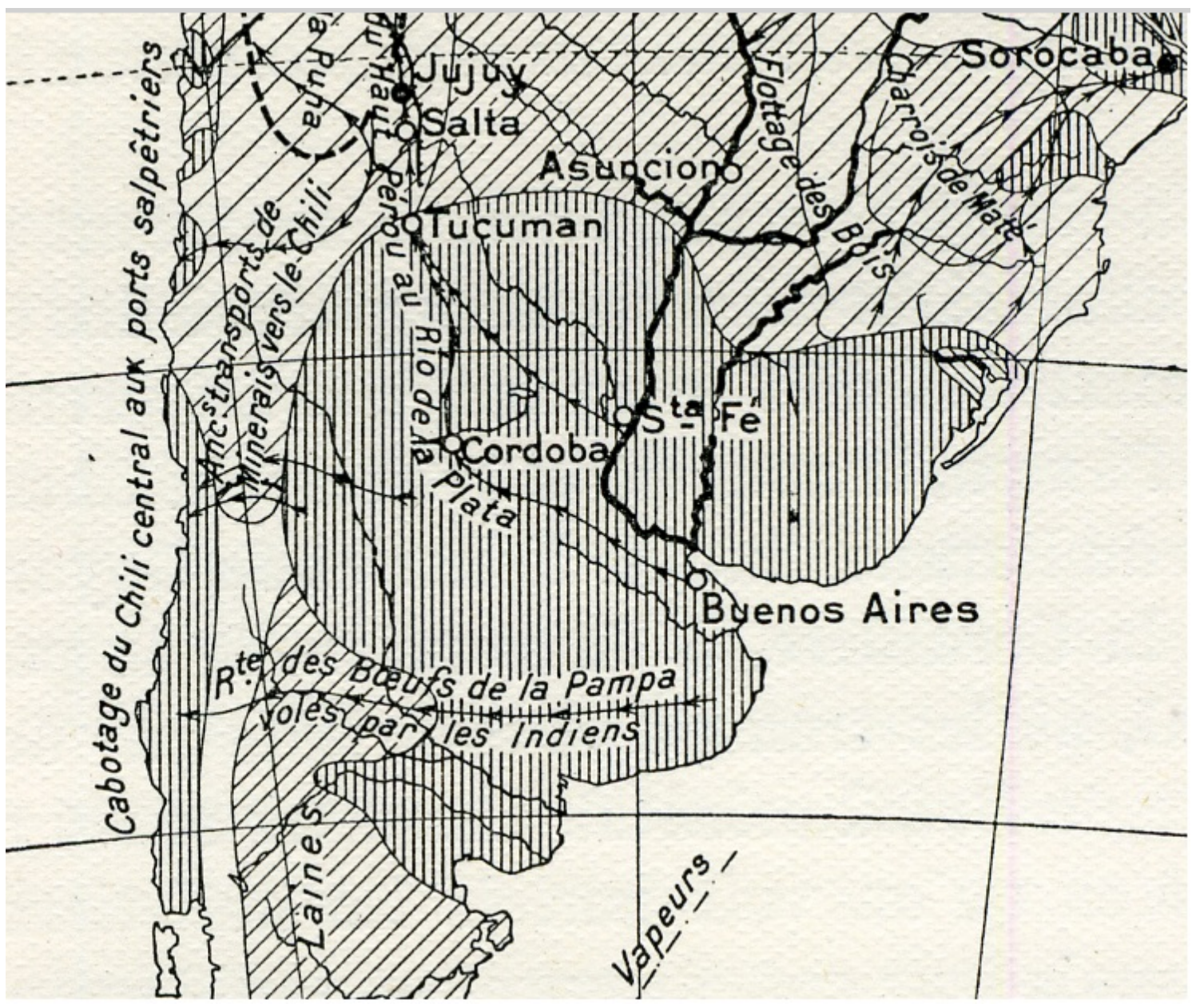

Fuente: Denis, 1927:61 (detalle). Las zonas del Noroeste argentino y Misiones rayadas en diagonales gruesas indican "Regiones de arreos o transportes por bestias de carga"; las zonas del Chaco, Corrientes y Patagonia rayadas en diagonales más finas indican "Regiones donde circulan carros"; y la región rioplatense rayada en vertical indica "Regiones con una red densa de vías férreas".

En el caso del corredor norpatagónico, la articulación con el mercado nacional no significó, inicialmente, el cierre del tránsito de ganado hacia Chile sino simplemente su cambio de manos: los mediadores dejaron de ser los grupos indígenas independientes y pasaron a ser las empresas terratenientes que ya producían ganado en la Pampa y lo exportaban a los mercados atlánticos. Los dos proyectos de ferrocarriles funcionales a ese circuito - el Ferrocarril del Sur, de una empresa inglesa, trazado entre Bahía Blanca y Zapala, y el ferrocarril estatal de San Antonio Oeste al Nahuel Huapi- se iniciaron a fines del siglo XIX con el propósito de llegar a puertos chilenos, pero sus obras se detuvieron en la coyuntura económica crítica que precedió y acompañó a la Primera Guerra Mundial. Las vías llegaron a Zapala en 1913 y a San Carlos de Bariloche 
recién en 1934. A partir de los años '20 y hasta los '40 se dieron tres procesos complementarios: en primer lugar, el cierre de la frontera argentino-chilena para la circulación de mercaderías y personas; en segundo lugar, la formación de actividades y circuitos económicos locales - el turismo en torno del Nahuel Huapi; la ganadería ovina en la meseta patagónica; la agricultura bajo riego en el Alto Valle del río Negro-; y, finalmente, la reversión de la circulación que antes respondía a la demanda de los mercados chilenos y ahora pasaba a reaccionar a la demanda de los puertos atlánticos y de los mercados internacionales con los que ellos se vinculaban.

En las últimas dos décadas, los procesos paralelos de globalización del capitalismo y de democratización de la región dieron lugar a un cambio de paradigma en las relaciones internacionales, marcadas antes por el recelo y las hipótesis de conflicto y ahora por el acercamiento y los procesos de integración. La tradicional circulación de personas y los vínculos sociales a lo largo del corredor bioceánico encarnados, por ejemplo, en las sucesivas oleadas de inmigración chilena a la Norpatagonia- no se han perdido, y ahora se ven potenciados por nuevos factores. La misma lógica fragmentadora de la globalización capitalista produce también superposición de intereses, competencia en distintos niveles - entre corredores centrales y periféricos, entre sectores económicos dinámicos y letárgicos, entre actores sociales beneficiados y perjudicados, entre variantes de un mismo corredor (p.e., entre el "corredor neuquino" Bahía Blanca - Concepción y el "corredor rionegrino" San Antonio - Puerto Montt) y entre proyectos políticos-, y, como es inherente a cualquier proceso sociohistórico, una cierta conflictividad.

\section{b. Las áreas naturales protegidas y turistificadas}

Paralelamente, la iniciativa IIRSA incluye, para el Eje del Sur, un grupo de proyectos denominado "Corredor Turístico Binacional de la Zona de los Lagos" (figura 5) que comprende acciones de mejoramiento de la infraestructura de caminos y de integración de los controles fronterizos (figura 6), sin duda funcionales o facilitadores de la circulación de mercancías. 
Pedro Navarro Floria

Las viejas fronteras revisitadas: problematizando la formación territorial de los bordes de los Estados...

Figura 5 - Eje del Sur, mapa de grupos de proyectos

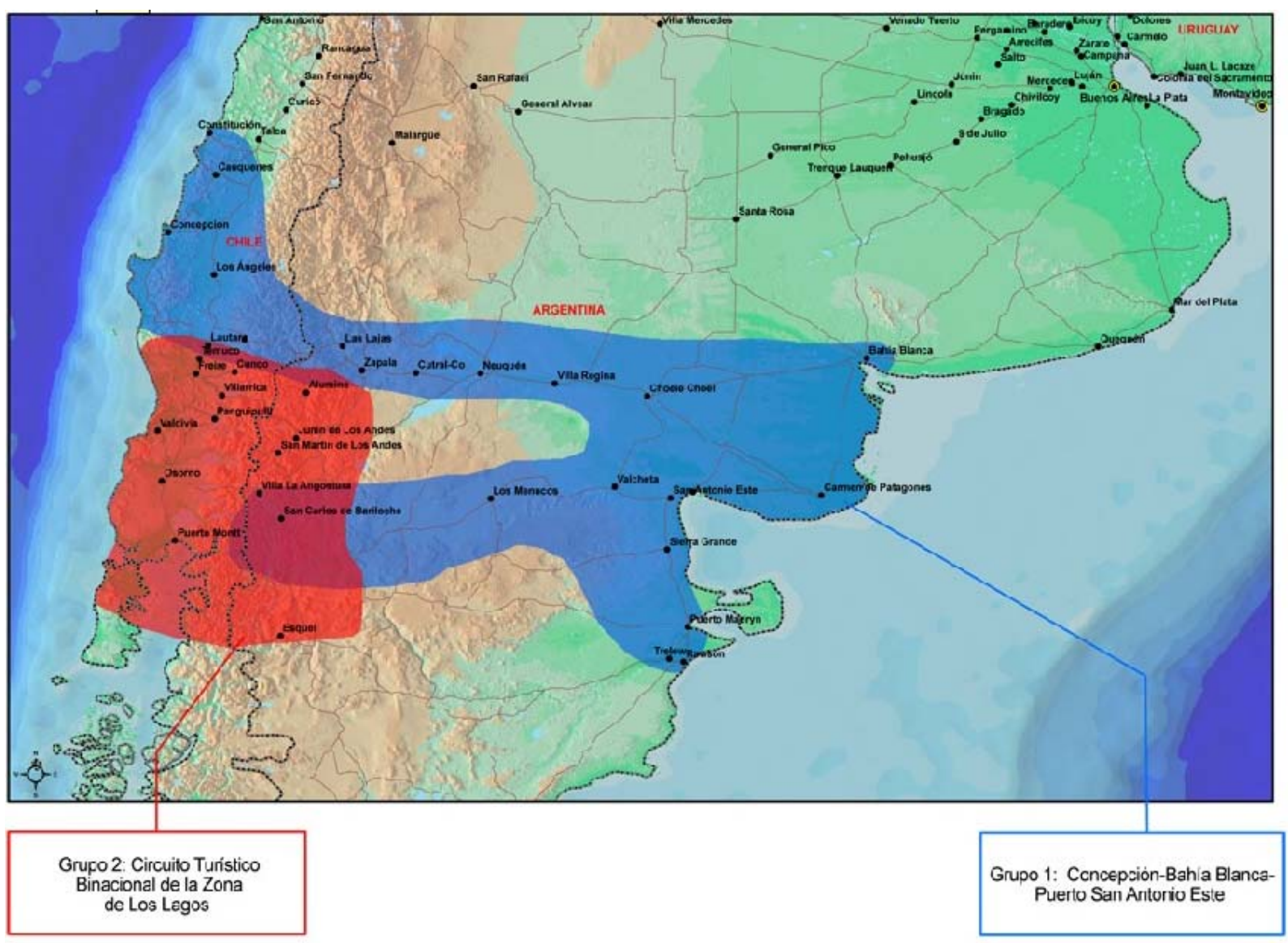

Fuente: http:// www.iirsa.org. 
Figura 6 - Eje del Sur, mapa de proyectos del Corredor Turístico Binacional de la Zona de los Lagos

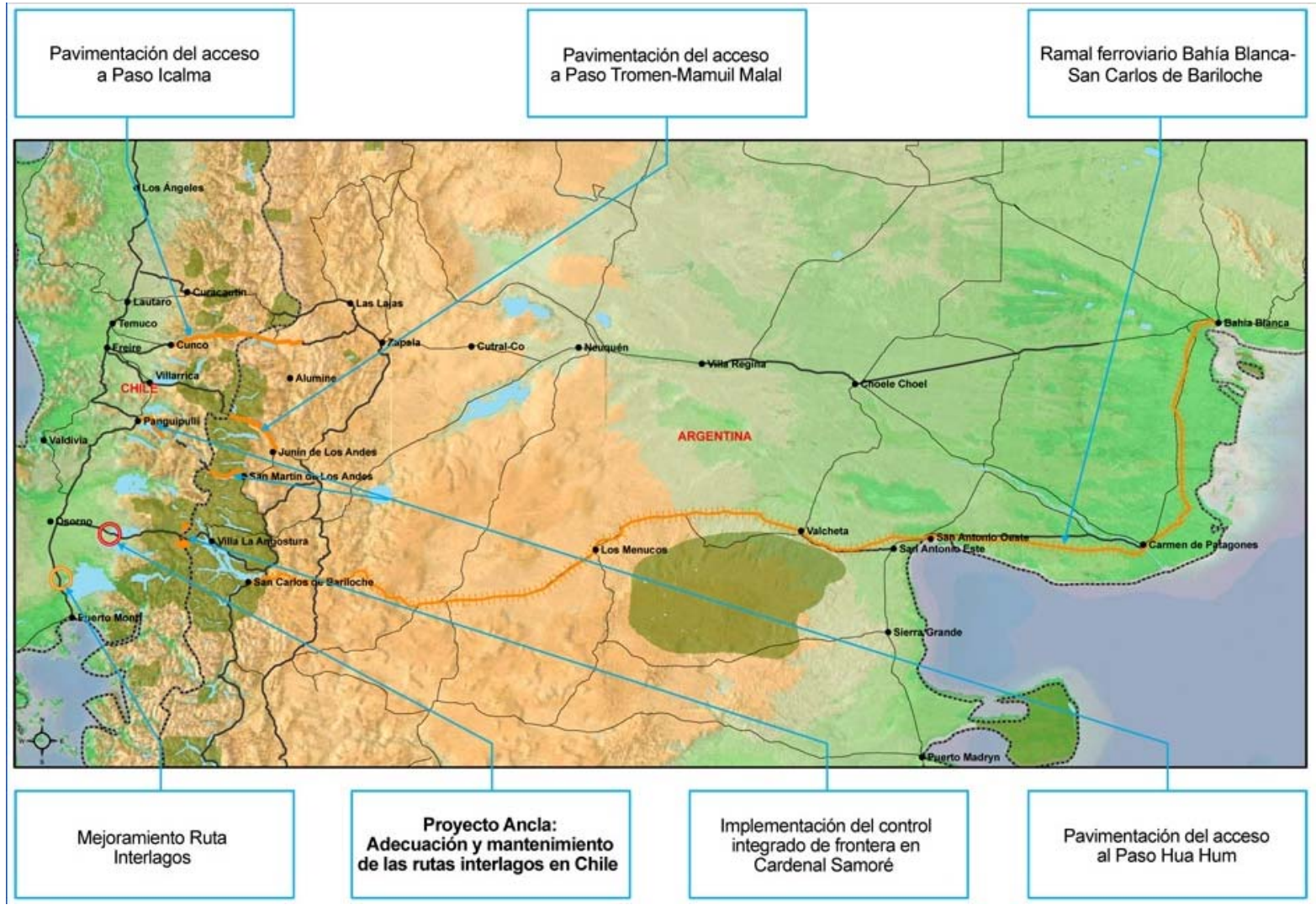

Fuente: http:// www.iirsa.org.

La idea de un área protegida binacional de uso turístico compartido es tan antigua como los mismos Parques Nacionales argentinos (NAVARRO FLORIA, 2008a; NAVARRO FLORIA; VEJ SBJ ERG, 2009). Cuando Francisco Moreno donó al Estado nacional una porción de tierra en el extremo occidental del lago Nahuel Huapi, en una zona limítrofe con Chile, para crear el Parque Nacional del Sur, en 1903, cuando acababa de resolverse pacíficamente la cuestión limítrofe más importante con el país hermano, propuso que Chile creara a su vez un área protegida adyacente y que juntas formaran una zona neutral. En el proyecto elaborado por el ingeniero estadounidense Bailey Willis, contratado por el gobierno argentino para realizar un estudio de la Patagonia Norte, en 1914, se retoma la idea del parque binacional en el marco de una idea de uso turístico democrático de los recursos regionales. La misma concepción integradora del espacio turistificado aparece en los proyectos de Emilio Frey, un actor clave en el proceso territorial local. Frey había sido colaborador tanto de Moreno en la Comisión de Límites como de Willis en la Comisión del Paralelo 41ำ, desde 1922 fue intendente del Parque Nacional del Sur, y luego fundador del Club Andino Bariloche, intendente de San Carlos de Bariloche y del Parque Nacional Nahuel Huapi, etc. La red 
intelectual se cierra con la presencia de Theodore Roosevelt en el Nahuel Huapi en 1913, promoviendo la política de parques nacionales como parte de la paradiplomacia propia de la iniciativa panamericanista (ZUSMAN, 2010).

Chile creó, efectivamente, el Parque Nacional Vicente Pérez Rosales en 1926, pero entre las décadas de 1930 y 1990, en cambio, el impulso integrador se vio interrumpido por políticas nacionalistas de ambos lados que tendieron tanto a cerrar las fronteras con los países limítrofes como a integrar económicamente cada país con mercados extrarregionales. Esto no impidió que la política de parques nacionales continuara desarrollándose en la Argentina, sino todo lo contrario: la creación de la Dirección estatal correspondiente y del Parque Nacional Nahuel Huapi contienen un proyecto explícito de nacionalización de la frontera, encubriendo incluso el propósito, menos evidente, de crear una zona de control militar disfrazada de área natural protegida (NAVARRO FLORIA, 2008b). Lo interesante es el modo en que, tanto en el contexto del panamericanismo de principios del siglo XX como en el de los nacionalismos de entreguerras, la creación de parques nacionales en la Norpatagonia funcionó como pantalla encubridora de iniciativas políticas de mayor alcance. Nada indica que el caso del proyecto IIRSA sea diferente.

La Organización de las Naciones Unidas para la Educación, la Ciencia y la Cultura (UNESCO) acaba de crear una Reserva de Biosfera en el área cordillerana austral de Chile y Argentina (figura 7). La creación de una reserva de este tipo por un organismo supranacional implica la revalorización y un cierto grado de internacionalización de un espacio considerado marginal por los Estados argentino y chileno. También implica, en la medida en que las mismas Naciones Unidas buscan promover la creación de áreas protegidas transfronterizas y que los propios Estados nacionales afectados se involucran en una decisión de este tipo - como es, por lo menos, en el caso presente, un condicionamiento y una orientación para el proceso de integración binacional. Territorios fiscales de reserva natural, parques nacionales, etc., creados a partir de la valorización estética y simbólica de determinados paisajes para su disfrute y/o su explotación nacional, son recreados actualmente en un contexto mundial diferente, internacionalizados o privatizados con el aparente propósito de habilitar la depredación de los espacios no reservados - las "zonas de sacrificio"- y/ o la transformación del wilderness - lo intacto, lo virgen, lo salvaje en mercancía. Lo llamativo vuelve a ser, como en tantos otros casos, la regularidad con que procesos históricos similares atraviesan simultáneamente a toda América Latina. 
Pedro Navarro Floria

Las viejas fronteras revisitadas: problematizando la formación territorial de los bordes de los Estados...

Figura 7 - Mapa de la Reserva de Biosfera Andina Norpatagónica creada por la UNESCO

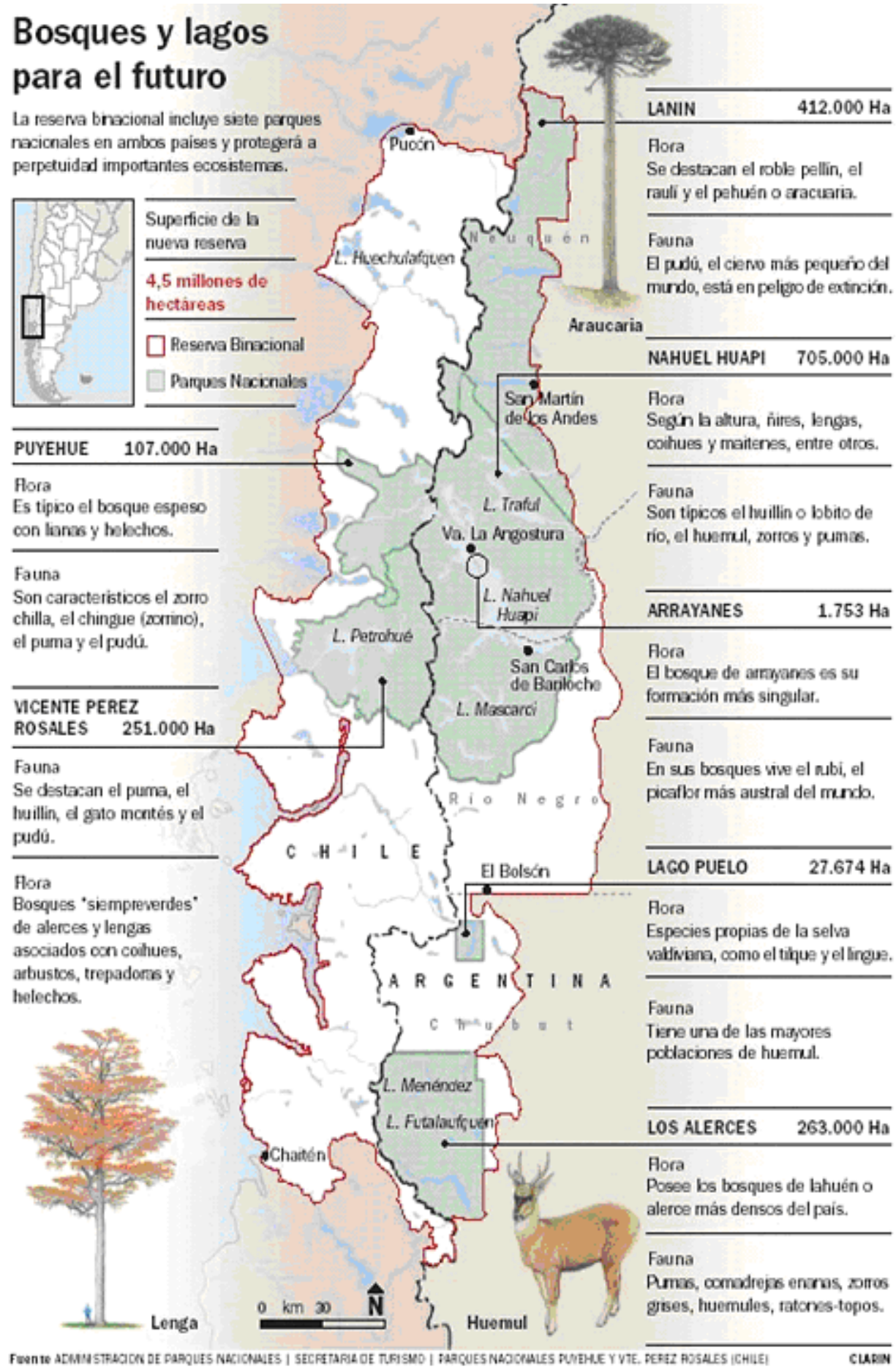

Fuente: diario Clarín (Buenos Aires). 


\section{Conclusiones}

A partir de una visión de la historia que la convierte en herramienta para pensar nuestro futuro social, proponemos profundizar el análisis de las vinculaciones entre procesos del pasado y problemas territoriales del presente en las fronteras, bordes o espacios marginales latinoamericanos. Una mirada comparada sobre los procesos territoriales latinoamericanos demuestra, en efecto, que son posibles de explicar, desde la historia, las debilidades estructurales de los espacios marginales algunos de los cuales hoy devienen en estratégicos en función de sus recursos, su ubicación, etc.- y las razones por las cuales su deficiente y tardía articulación con los sistemas estatales-nacionales facilita su actual internacionalización y sumisión a lógicas extrarregionales, a menudo en tensión con los intereses y necesidades locales. Esto constituye un nuevo foco de interés para los estudios históricos sobre las áreas fronterizas.

Como parte de ese estudio comparativo, la historiografía latinoamericana viene prestando una atención creciente a los procesos de formación territorial, problematizando y cuestionando el paradigma estatal-nacional tradicional. Desde nuestra experiencia historiográfica sobre un espacio marginal de la Argentina, la Norpatagonia, proponemos el trazado de una cronología que nos permita distinguir y caracterizar etapas, identificar las funciones que los territorios marginales han jugado respecto de sus centros de poder en cada etapa histórica, y determinar las tensiones entre lo local y lo global que han direccionado en el pasado y direccionan en el presente los procesos espaciales. Estas operaciones nos llevan a observar un contenido histórico importante en dos grupos de proyectos que actualmente se desarrollan en la región y que nos sirven como casos de observación: el de un circuito turístico binacional y el de un corredor comercial bioceánico, ambos funcionales al sistema de decisiones racionales del capitalismo globalizado.

El análisis histórico y comparativo permite establecer regularidades en los procesos de formación territorial. La más evidente de esas constantes nos indica que en las épocas en que se proyectaron con mayor fuerza sobre las áreas marginales las expectativas e intereses del poder económico y político externo y hegemónico, a través de iniciativas coloniales o neocoloniales, se instalaron sistemas extractivos de recursos y de población, se intensificaron las fracturas entre actores dinámicos/rentables y letárgicos/no rentables y se produjo un crecimiento desigual y conflictivo, cuando no una desertificación lisa y llana. La hipótesis que ayuda a explicar esos fenómenos apunta que las debilidades estructurales de una formación territorial marcada por el colonialismo interno favorecen la articulación vertical o funcionalización por actores 
hegemónicos del capital internacional sin consideración de los intereses y necesidades de desarrollo local.

\section{Referencias}

BAUER, Arnold. La Hispanoamérica rural, 1870-1930. In: BETHELL, Leslie (Ed.). Historia de América Latina. Barcelona: Crítica, 1991. t. 7, p. 133-162.

BERVEJ ILLO, Federico. Territorios en la globalización. Cambio global y estrategias de desarrollo territorial. 1996. Disponible en: <http:// moodle.eclac.cl/ file.php/ 1/ documentos/ grupo2/territorios_en_la_glob.pdf>. Aceso en: 29 out. 2007.

BOHOSLAVSKY, Ernesto. Territorio y nacionalismo en Argentina, 1880-1980: del espacio al cuerpo nacional. In: ENCUENTRO DE LATINOAMERICANISTAS ESPAÑOLES: Viejas y nuevas alianzas entre América Latina y España. 2006. Disponible en:<http:/ / halshs.archives-ouvertes.fr/ docs/ 00/ 10/ 42/ 25/ PDF/ BOHOSLAVSKI.pdf>. Aceso en: 24 out. 2007.

BOHOSLAVSKY, Ernesto. Los mitos conspirativos y la Patagonia en Argentina y Chile durante la primera mitad del siglo XX: orígenes, difusión y supervivencias. 2006b. Tesis doctoral - Universidad Complutense de Madrid, Madrid.

CAVALERI, Paulo. La restauración del Virreinato. Orígenes del nacionalismo territorial argentino. Bernal: Universidad Nacional de Quilmas, 2004.

CEPPARO, María Eugenia; PRIETO, Estela B. Avances y retrocesos en la valoración del paso Pehuenche como alternativa de comunicación bioceánica en el marco del MERCOSUR. In: ENCUENTRO INTERDISCIPLINAR DE DEBATE SOBRE MERCOSUR, 2008, Neuquén. Actas... Neuquén: Universidad Nacional del Comahue, 2008.

ESVERTIT COBES, Natàlia. La visión del Estado ecuatoriano sobre el Oriente en el siglo XIX. Reflexiones en torno a la legislación (1830-1895). In: GARCÍA J ORDÁN, Pilar; SALA I VILA, Núria (coord.). La nacionalización de la Amazonía. Barcelona: Universitat de Barcelona, 1998. p. 39-75.

FERNÁNDEZ BRAVO, Álvaro. Literatura y frontera. Procesos de territorialización en las culturas argentina y chilena del siglo XIX. Buenos Aires: Sudamericana/ Universidad de San Andrés, 1999.

Fontana, J osep. La Historia delos Hombres. Barcelona: Crítica, 2001.

GALAFASSI, Guido. Entre viejos y nuevos cercamientos. Las políticas de extracción de recursos y de ocupación del territorio en la Patagonia. In: DIMITRIU, Andrés M. (Comp.). ¿Nuevas fronteras con múltiples cercamientos? Hacia una revisión crítica de la política territorial y extractiva en la Patagonia. Roca: Publifadecs, 2010. p. 35-69.

HALPERIN DONGHI, Tulio. Reforma y disolución de los imperios ibéricos, 17501850. Madrid: Alianza, 1985. 
HALPERIN DONGHI, Tulio. Historia Contemporánea de América Latina. Madrid: Alianza, 1969.

HEVILLA, María Cristina. El estudio de la frontera en América. Una aproximación bibliográfica. Biblio 3W. Revista Bibliográfica de Geografía y Ciencias Sociales Barcelona, v. 125, 1998. In: <http:// www.ub.es/ geocrit/b3w-125.htm>. Aceso el: 24 out. 2007.

KLARÉN, Peter F. Los orígenes del Perú moderno, 1880-1930. In: BETHELL, Leslie (Ed.). Historia de América Latina. Barcelona: Crítica, 1991. t. 10, p. 233-279.

LACOSTE, Pablo. El Sistema Pehuenche. Frontera, sociedad y caminos en los Andes Centrales argentino-chilenos (1658-1997). Mendoza: Universidad Nacional de Cuyo y Gobierno de Mendoza, 1998.

LACOSTE, Pablo. La imagen del otro en las relaciones de la Argentina y Chile (15342000). Buenos Aires: FCE/ Universidad de Santiago de Chile, 2003.

LAGOS, Marcelo A.; SANTAMARÍA, Daniel J . Barcos en la selva. El Bermejo: un modelo frustrado de comunicación e intercambio. In: J ORNADAS DE HISTORIA DE LA PATAGONI, 3., 2008, San Carlos de Bariloche. Historia de la Patagonia. Neuquén: Universidad Nacional del Comahue, 2008. CD-ROM.

LEÓN SOLÍS, Leonardo. Araucanía: la violencia mestiza y el mito dela "pacificación", 1880-1900. Santiago: Universidad Arcis, 2005.

LOIS, Carla. Técnica, política y deseo territorial en la cartografía oficial de la Argentina (1852-1941). Scripta Nova. Revista electrónica de geografía y ciencias sociales (Barcelona), X-218-52, 2006. Disponible en: <http:// www.ub.es/geocrit/sn/ sn-21852.htm>. Aceso el: 24 out. 2007.

MAGNOLI, Demétrio. O corpo da pátria. Imaginação geográfica e política externa no Brasil (1808-1912). São Paulo: UNESP/ Moderna, 1997.

MOUTOUKIAS, Zacarías. Comercio y producción. In: ACADEMIA NACIONAL DE LA HISTORIA. Nueva Historia de la Nación Argentina. Buenos Aires: Planeta, 1999. t. 3. p. 51-103.

NAVARRO FLORIA, Pedro. Ciencia y política en la región norpatagónica: el ciclo fundador (1779-1806). Temuco: Universidad de La Frontera, 1994.

NAVARRO FLORIA, Pedro. El desierto y la cuestión del territorio en el discurso político argentino sobre la frontera sur. Revista Complutense de Historia de América, Madrid, v. 28, p. 139-168, 2002.

NAVARRO FLORIA, Pedro. La nacionalización fallida de la Patagonia Norte, 18621904. Quinto Sol, Santa Rosa, v. 7, p. 61-91, 2003.

NAVARRO FLORIA, Pedro. Paisajes del progreso. La Norpatagonia en el discurso científico y político argentino de fines del siglo XIX y principios del XX. Scripta Nova. Revista electrónica de geografía y ciencias sociales, Barcelona, X-218-76, $2006 a$. 
NAVARRO FLORIA, Pedro. Guerra de frontera y guerra de representaciones. Avances y perspectivas sobre la frontera y su historiografía en el siglo XIX. 2006b. In: J ORNADA ACADÉMICA DE DISCUSIÓN DE AVANCES DE INVESTIGACIÓN EN HISTORIA ARGENTINA: fuentes, problemas y métodos, 2006, Rosario.

NAVARRO FLORIA, Pedro (Coord.). Paisajes del progreso. La resignificación de la Patagonia Norte, 1880-1916. Neuquén, EdUCo/ CEP, 2007.

NAVARRO FLORIA, Pedro. La 'Suiza argentina', de utopía agraria a postal turística. La resignificación de un espacio entre los siglos XIX y XX. In: J ORNADAS DE HISTORIA DE LA PATAGONI, 3., 2008, San Carlos de Bariloche. Historia de la Patagonia. Neuquén: Universidad Nacional del Comahue, 2008a. CD-ROM

NAVARRO FLORIA, Pedro. El proceso de construcción social dela región del Nahuel Huapi en la práctica simbólica y material de Exequiel Bustillo (1934-1944). Pilquén: Universidad Nacional del Comahue, Viedma, 2008b.

NAVARRO FLORIA, Pedro; VEJ SBJ ERG, Laila. El proyecto turístico barilochense antes de Bustillo: entre la prehistoria del Parque Nacional Nahuel Huapi y el desarrollo local. Estudios y Perspectivas en Turismo, Buenos Aires, v. 18, n. 4, p. 414-433, 2009.

NICOLAU, Marcelo da Costa. Olhares do Estado Novo sobre a Amazônia. In: LOIS, Carla (Coord.). Imágenes y lenguajes cartográficos en las representaciones del espacio y del tiempo. Buenos Aires: Universidad de Buenos Aires, 2006.

NOCETTI, Oscar R.; MIR, Lucio B. La disputa por la tierra. Tucumán, Río de la Plata y Chile, 1531-1822. Buenos Aires: Sudamericana, 1997.

PINTO RODRÍGUEZ, J orge. La Araucanía en el imaginario de autoridades, empresarios e intelectuales chilenos, 1850-1930. In: J ORNADAS INTERESCUELAS, 11., 2007, Tucumán.

QUIJ ADA, Mónica. Imaginando la homogeneidad: la alquimia de la tierra. In: QUIJ ADA, Mónica; BERNAND, Carmen; SCHNEIDER, Arnd. Homogeneidad y nación. Con un estudio de caso: Argentina, siglos XIX y XX. Madrid: CSIC, 2000. p. 179-217.

ROCK, David. Argentina en 1914: las pampas, el interior, Buenos Aires. In: BETHELL, Leslie (Ed.). Historia de América Latina. Barcelona: Crítica, 1991. t. 10. p. 67-88.

ROFMAN, Alejandro; ROMERO, Luis Alberto. Sistema socioeconómico y estructura regional en la Argentina. 2. ed. Buenos Aires: Amorrortu, 1997.

ROULET, Florencia; FLORIA, Pedro Navarro. De soberanos externos a rebeldes internos: la domesticación discursiva y legal de la cuestión indígena en el tránsito del siglo XVIII al XX. Boletín TEFROS, Río Cuarto, 2005.Disponible en:<http:// www.tefros.com.ar/ tefros/ revista/v3n1p05/ completos/ soberanosext.pdf>. Aceso en: 24 out. 2007.

RUFFINI, Martha. La pervivencia de la República posible en los territorios nacionales. Poder y ciudadanía en Río Negro. Bernal: Universidad Nacional de Quilmas, 2007. 
SALA I VILA, Núria. La proyección de la legislación estatal amazónica en la selva sur del Perú (1898-1930). In: GARCÍA J ORDÁN, Pilar; SALA I VILA, Núria (Coord.). La nacionalización de la Amazonía. Barcelona: Universitat de Barcelona, 1998. p. 77-98.

SANTOS, Milton. Los espacios de la globalización. Anales de Geografía de la Universidad Complutense, Madrid, v.13, p. 69-77, 1993.

SCHRÖTER, Bernd. La frontera en Hispanoamérica colonial: un estudio historiográfico comparativo. Colonial Latin American Historical Review, Albuquerque NM, v.10, p. 351-385, 2001.

SERJ E, Margarita. El revés de la nación: territorios salvajes, fronteras y tierras de nadie. Bogotá: Uniandes, 2005.

TERUEL, Ana A. El borde occidental del Chaco argentino: los intentos de integración al Estado-nación en la segunda mitad del siglo XIX”. In: GARCÍAJ ORDÁN, Pilar; SALA I VILA, Núria (Coord.). La nacionalización de la Amazonía. Barcelona: Universitat de Barcelona, 1998. p. 155-174.

VIVES AZANCOT, Pedro A. Espacios económicos en América, siglo XVIII. In: COLOQUIO FRANCO-ESPAÑOL, MAISON DES PAYS IBÉRIQUES, 1986. La América Española en la época de las Luces. Tradición - Innovación - Representaciones, Burdeos. Madrid: Cultura Hispánica, 1988. p. 173-182.

ZUSMAN, Perla. Panamericanismo y conservacionismo en torno al viaje de Theodore Roosevelt al Norte de la Patagonia (1913). In: J ORNADAS DE HISTORIA DE LA PATAGONIA, 2010, Santa Rosa.

Colaboración recibida en 14/03/2011 y aprobado en 10/07/ 2011. 
Pedro Navarro Floria

Las viejas fronteras revisitadas: problematizando la formación territorial de los bordes de los Estados... 